\title{
The Co-Expression of Kallikrein 5 and Kallikrein 7 Associates with Poor Survival in Non-HPV Oral Squamous-Cell Carcinoma
}

\author{
Frank K.J. Leusink ${ }^{a} \quad$ P.J. van Diest ${ }^{b} \quad$ M.H. Frank ${ }^{a} \quad$ R. Broekhuizen ${ }^{b} \quad$ W. Braunius ${ }^{c}$ \\ S.R. van Hooff ${ }^{d}$ Stefan M. Willems ${ }^{b} \quad$ R. Koole ${ }^{a}$ \\ Departments of a Oral and Maxillofacial Surgery, ${ }^{b}$ Pathology, ${ }^{c}$ Otolaryngology, Head and Neck Surgery, and \\ ${ }^{\mathrm{d}}$ Molecular Cancer Research, University Medical Centre Utrecht, Utrecht, The Netherlands
}

\section{Key Words}

Oral squamous cell carcinoma $\cdot$ Kallikrein $5 \cdot$ Kallikrein 7 .

Serine protease inhibitor Kazal-type 5

\begin{abstract}
Objective: Oral squamous-cell carcinoma (OSCC) still has a poor prognosis. Lymph node metastasis (LNM) is a major determinant of treatment decisions and prognosis. Serine protease inhibitor Kazal-type 5 (SPINK5) is the inhibitor of kallikrein 5 (KLK5) and KLK7. SPINK5, KLK5 and KLK7 are three of the genes of a recently validated LNM-predicting gene expression profile in OSCC. This study evaluates their clinicopathological role and value as biomarkers in OSCC. Methods: Eighty-three patients with primary OSCC, treated surgically between 1996 and 2000, were included. Gene expression data were acquired from a previously reported study. Human papillomavirus (HPV) status was determined by an algorithm for HPV-16. Protein expression for KLK5, KLK7 and SPINK5 was semi-quantitatively determined in all 83 tumours by immunohistochemistry. All expression data were correlated with clinicopathological parameters. Results: Concurrent loss of KLK5 and KLK7 correlates with worse disease-specific and overall survival (DSS and OS). Multivariate analysis proved that co-expression is an inde-
\end{abstract}

pendent prognostic factor for DSS $(p=0.029)$ and OS $(p=$ $0.001)$. Conclusion: This report demonstrates that concurrent loss of KLK5 and KLK7 associates with a poor clinical outcome in OSCC and could therefore serve as prognostic marker in this disease.

(c) 2015 S. Karger AG, Basel

\section{Introduction}

Oral squamous cell carcinoma (OSCC) is the most common type of head and neck tumour worldwide [1]. Tobacco-smoking, betel-nut chewing, alcohol consumption and human papillomavirus (HPV) infection are the major risk factors $[2,3]$. Despite advances in surgery, radiation and chemotherapy, the prognosis for OSCC patients remains poor, with a 5-year survival rate of approximately $50 \%$. Lymph node metastasis (LNM) of OSCC is a major determinant of prognosis and treatment but can be difficult to detect with current diagnostic modalities [4]. Approximately $30-40 \%$ of LNMs are left undetected

P.J. van Diest, M.H. Frank, S.M. Willems and R. Koole contributed equally to this work.

\section{KARGER 125}

C) 2015 S. Karger AG, Base

$1015-2008 / 15 / 0822-0058 \$ 39.50 / 0$

E-Mail karger@karger.com

www.karger.com/pat
Stefan M. Willems

Department of Pathology

University Medical Centre Utrecht, H4.2.24

Heidelberglaan 100, 3584 CX Utrecht (The Netherlands)

E-Mail S.M.Willems-4@ umcutrecht.nl 
Fig. 1. Schematic representation of the work flow of this study. Previous studies resulted in the discovery and validation of a multi-gene signature [19-21]. In this study, gene expression data [20] were used to correlate the selected genes KLK5, KLK7 and their cognate inhibitor SPINK5 with clinical and histopathological parameters. From the same cohort of tumour samples, a TMA was constructed for immunohistochemical analysis of the selected genes to correlate their protein expression with clinical and histopathological parameters, and outcomes were compared.

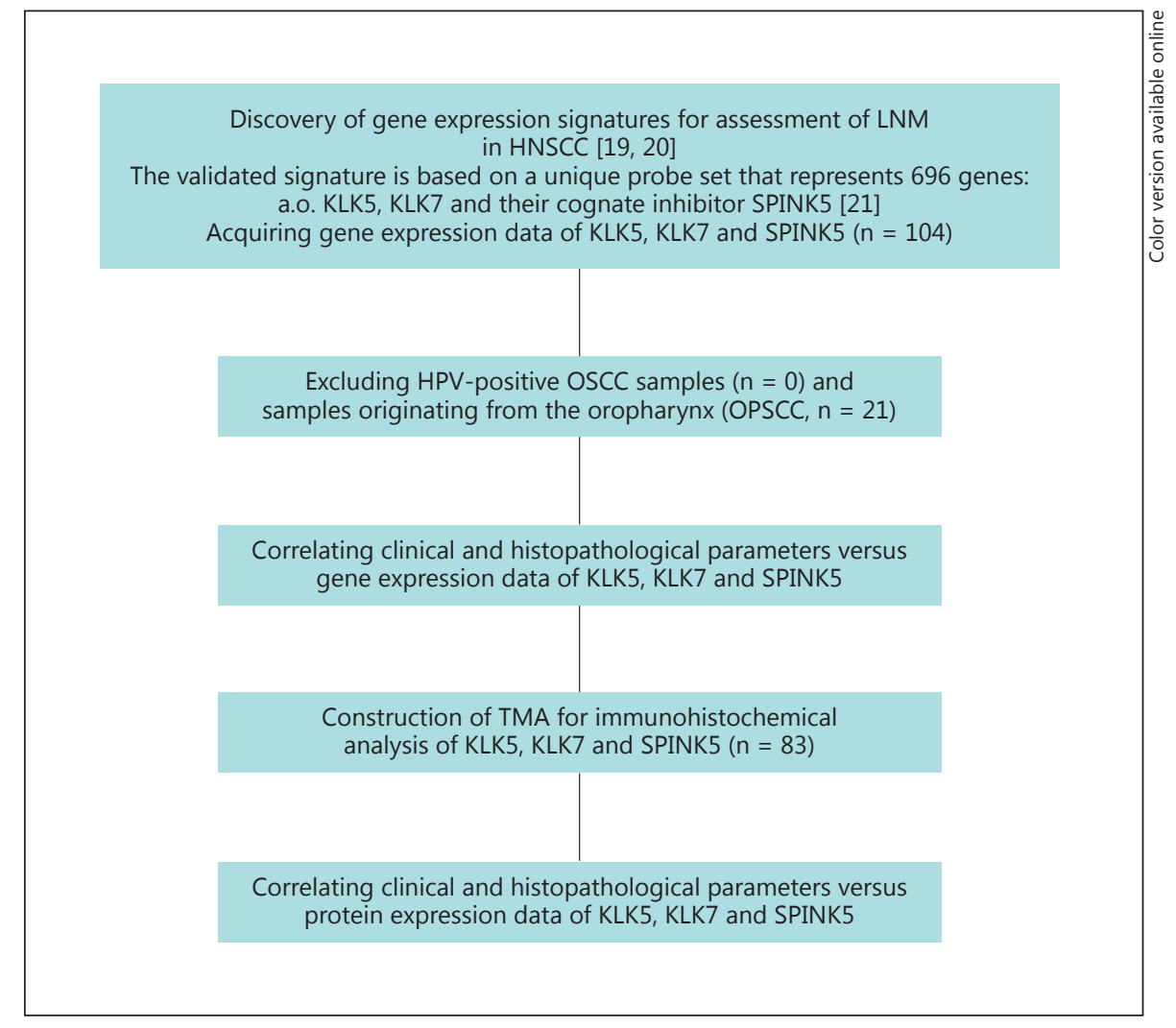

in this population, and will develop into overt neck disease during follow-up when left untreated. Therefore, treatment of the neck is recommended even when the tumour has been classified as clinically node-negative. This results in unnecessary treatment and morbidity in 60$70 \%$ of patients with OSCC. Additional biological markers for occult metastasis may improve staging [4]. Human-tissue kallikreins (KLKs), a family of 15 secreted serine proteases encoded by a multi-gene cluster (KLK genes) on chromosome 19q13.47, may be such biomarkers [5]. These genes play different functional roles like semen liquefaction by digestion of Seminigelin by the most commonly known, KLK3, better known as prostate-specific antigen $[6,7]$ and skin desquamation by cleaving corneodesmosomes by KLK5 and KLK7 [8]. KLKs have been implicated in different cancer types $[5,6,8-10]$ and co-expression of KLK5 and KLK7 is often reported [9, 11, 12]. In addition, in OSCC, over-expression of KLK5, KLK7, KLK8 and KLK10 has been reported [13], but correlations with clinical and pathological parameters (especially nodal disease) were not analyzed.

Lymphoepithelial Kazal-type-related inhibitor (LEKTI), the product of the gene encoding for serine pro- tease inhibitor Kazal-type 5 (SPINK5) inhibits KLK5 and KLK7 [14-16]. In head and neck squamous cell carcinoma (HNSCC), SPINK5 expression is down-regulated both at the mRNA and protein levels $[17,18]$. Moreover, SPINK5, KLK5 and KLK7 are all part of the signature genes for predicting LNMs in HNSCC $[19,20]$ including OSCC [21].

Here, we further characterized the value of KLK5, KLK7 and SPINK5 as biomarkers of LNM and prognosis in primary OSCCs.

\section{Materials and Methods}

Patients and Tissue Samples

The source population consisted of patients with a histologically confirmed HNSCC, primarily treated with surgery and radiotherapy (on indication) between 1996 and 2000 at the University Medical Centre, Utrecht (table 1), previously described in an earlier reported gene expression profiling study [20]. Tissues were used in line with the code 'Proper Secondary Use of Human Tissue' as installed by the Dutch Federation of Biomedical Scientific Societies [22].

Study inclusion was based on: (1) the oral cavity as primary tumour site, (2) HPV-16 status, excluding positive tumours and (3) a follow-up time of $>5$ years. Patients with a synchronous primary tumour or a previous malignancy in the head and neck region were 
Table 1. Clinical characteristics of the included OSCC patients

\begin{tabular}{|c|c|c|}
\hline & $\mathrm{n}$ & $\%$ \\
\hline Total & 83 & 100 \\
\hline \multicolumn{3}{|l|}{ Gender } \\
\hline Female & 36 & 43 \\
\hline Male & 47 & 57 \\
\hline \multicolumn{3}{|l|}{ Age at diagnosis } \\
\hline $0-60$ years & 53 & 64 \\
\hline$\geq 61$ years & 30 & 36 \\
\hline Median age, years (range) & 62 & $(37-87)$ \\
\hline \multicolumn{3}{|l|}{ Smoking history } \\
\hline Current smoker/ceased $<1$ year ago & 58 & 70 \\
\hline Ex-smoker/ceased $>1$ year ago & 9 & 11 \\
\hline Never-smoker & 15 & 18 \\
\hline \multicolumn{3}{|l|}{ Alcohol consumption } \\
\hline$\geq 5 \mathrm{U} /$ day & 19 & 23 \\
\hline 1-4 U/day & 28 & 34 \\
\hline Occasionally & 17 & 20 \\
\hline Never & 19 & 23 \\
\hline \multicolumn{3}{|l|}{ Clinical T stage } \\
\hline $\mathrm{cT}_{1}$ & 13 & 16 \\
\hline $\mathrm{cT}_{2}$ & 31 & 37 \\
\hline $\mathrm{cT}_{3}$ & 8 & 10 \\
\hline $\mathrm{cT}_{4}$ & 31 & 37 \\
\hline \multicolumn{3}{|l|}{ Clinical N stage } \\
\hline cN0 & 53 & 64 \\
\hline $\mathrm{cN} 1-3$ & 30 & 36 \\
\hline \multicolumn{3}{|l|}{ Sub-site } \\
\hline Tongue & 30 & 36 \\
\hline Floor of mouth & 35 & 42 \\
\hline Buccal cavity & 10 & 12 \\
\hline Gum & 8 & 10 \\
\hline Mean follow-up time, months & 45 & \\
\hline
\end{tabular}

excluded. Tumours were selected on the availability of representative FFPE (formaldehyde-fixed, paraffin-embedded) tissue blocks and frozen-tissue samples of the primary tumour. Twenty-one patients were excluded due to their primary tumour originating from the oropharynx. HPV-16 positivity was determined in the remaining OSCC patients, so there were no further exclusions. In total, 83 tissue samples met the inclusion criteria. All investigators, apart from the study statistician, were blinded to the outcome of patients throughout all the analyses. The work flow of this study is illustrated in figure 1.

Representative hematoxylin and eosin (HE) slides of 83 OSCC were selected and reviewed by 2 experienced head and neck pathologists (P.J.v.D. and S.M.W.; table 2). A tissue microarray (TMA) was then made of the FFPE tissue blocks. Two central and two peripheral tissue cylinders with a diameter of $0.6 \mathrm{~mm}$ were punched out of the blocks, avoiding areas of necrosis, and then arrayed in a recipient paraffin block. Normal epithelium from the floor of the mouth, the gingiva and tonsil tissue was incorporated in each block to ensure similarity of staining in the different blocks, and to compare tumour staining with that of normal epithelium.
Table 2. Pathological characteristics of the included OSCC patients

\begin{tabular}{|c|c|c|}
\hline & $\mathrm{n}$ & $\%$ \\
\hline Total & 83 & 100 \\
\hline \multicolumn{3}{|l|}{ Pathological T stage } \\
\hline $\mathrm{pT}_{1}$ & 17 & 20 \\
\hline $\mathrm{pT}_{2}$ & 27 & 33 \\
\hline $\mathrm{pT}_{3}$ & 10 & 12 \\
\hline $\mathrm{pT}_{4}$ & 29 & 35 \\
\hline \multicolumn{3}{|l|}{ Pathological N stage } \\
\hline pNo & 38 & 46 \\
\hline $\mathrm{pN} 1-3$ & 45 & 54 \\
\hline \multicolumn{3}{|l|}{ Stage grouping } \\
\hline I & 14 & 17 \\
\hline II & 9 & 11 \\
\hline III & 22 & 26 \\
\hline \multicolumn{3}{|l|}{ Infiltration depth } \\
\hline$\geq 4.0 \mathrm{~mm}$ & 72 & 87 \\
\hline$<4.0 \mathrm{~mm}$ & 11 & 13 \\
\hline \multicolumn{3}{|l|}{ Differentiation grade } \\
\hline Good/moderate & 67 & 81 \\
\hline Poor/undifferentiated & 16 & 19 \\
\hline \multicolumn{3}{|l|}{ Keratinization } \\
\hline Present & 60 & 72 \\
\hline Absent & 20 & 24 \\
\hline Not available & 3 & 4 \\
\hline \multicolumn{3}{|l|}{ Vaso-invasion } \\
\hline Present & 18 & 22 \\
\hline Absent & 62 & 75 \\
\hline Not available & 3 & 3 \\
\hline \multicolumn{3}{|l|}{ Bone invasion } \\
\hline Present & 25 & 30 \\
\hline Absent & 58 & 70 \\
\hline \multicolumn{3}{|l|}{ Perineural growth } \\
\hline Present & 34 & 41 \\
\hline Absent & 39 & 47 \\
\hline Not available & 10 & 12 \\
\hline \multicolumn{3}{|l|}{ Spidery growth } \\
\hline Present & 65 & 78 \\
\hline Absent & 18 & 22 \\
\hline \multicolumn{3}{|l|}{ High-risk HPV status } \\
\hline Positive & 0 & 0 \\
\hline Negative & 83 & 100 \\
\hline
\end{tabular}

\section{KLK5, KLK7 and SPINK5 Gene Expression Analysis}

Genome-wide gene expression was measured using dual-channel microarrays with a pool of tumour samples as a reference as described earlier [20]. KLK5, KLK7 and SPINK5 were each represented by a single, unique feature on this array. The expression data were normalized for dye and print-tip biases using print-tip LOESS normalization, and variance stabilization was then applied [20]. The data and protocols used are publicly available (ArrayExpress E-UMCU-11).
60
Leusink et al. 

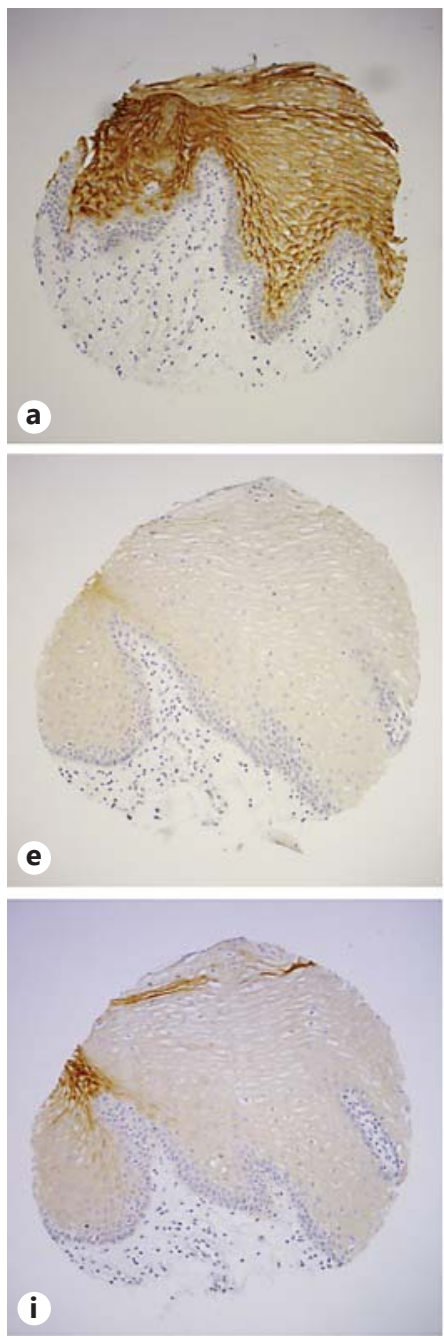

b
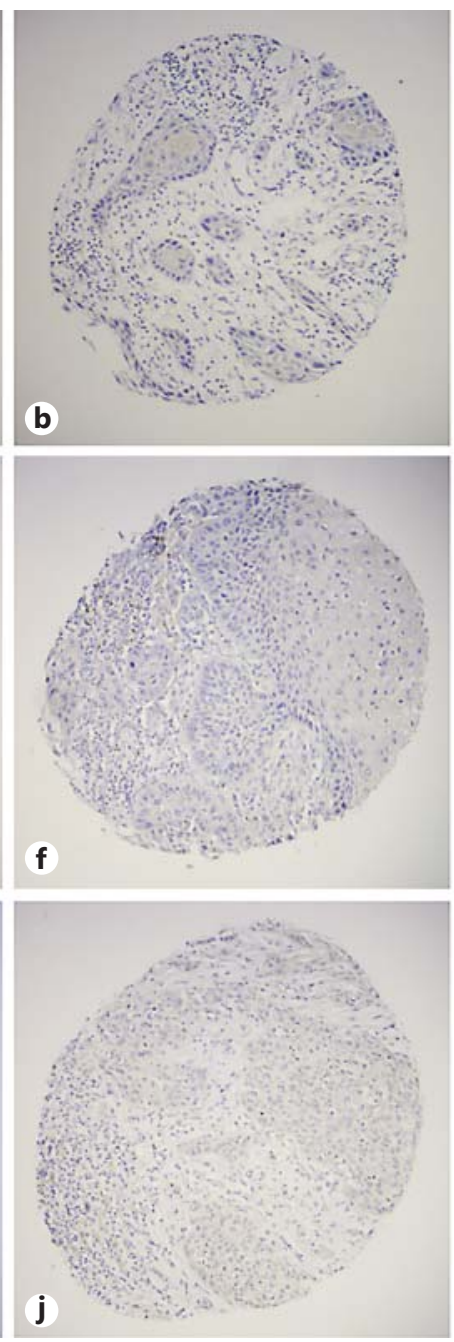
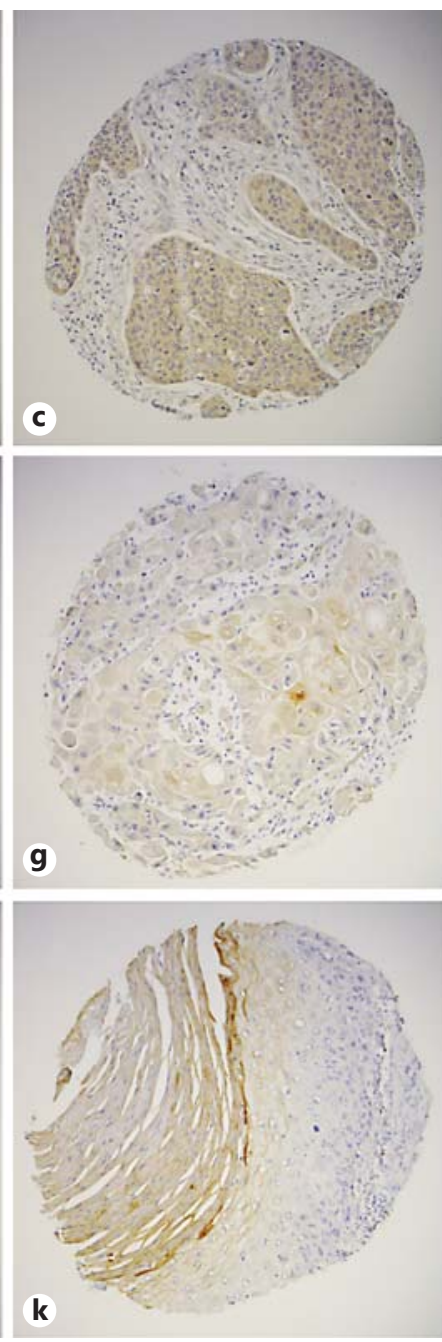
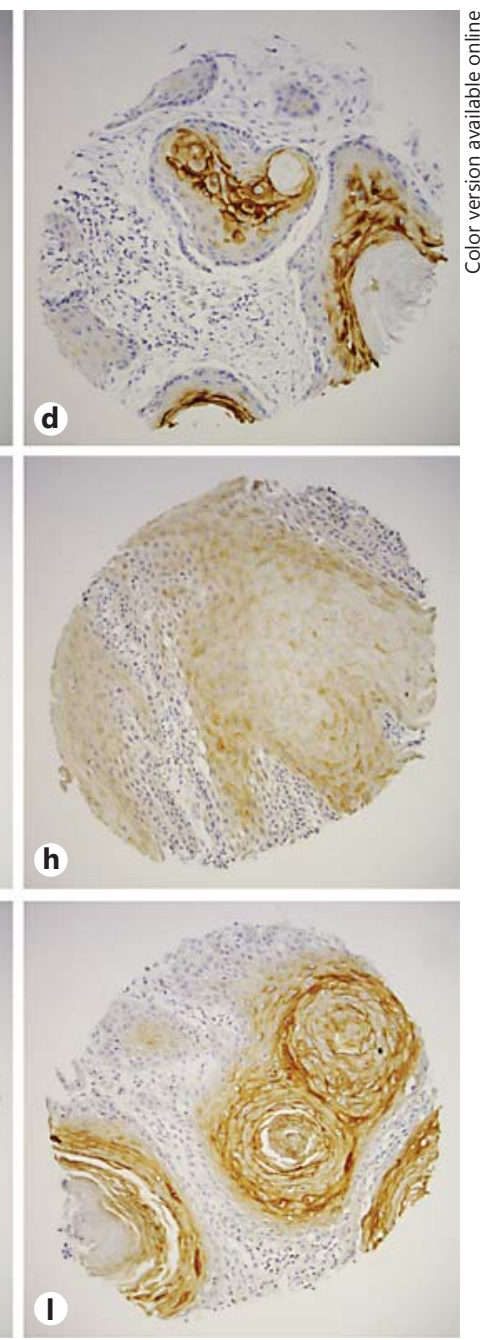

Fig. 2. KLK5, KLK7 and SPINK5 expression in OSCC and normal mucosa. Representative stainings of the TMA, consisting of 83 OSCC cases, are presented. Staining scores were calculated by the product of intensity (normal $=1$, strong $=2$ ) and the proportion of stained tumour cells (\%). SPINK5 staining: normal mucosa (a), no staining

\section{Detection of $H P V-16$}

HPV-16 active tumours were determined by a validated algorithm for the detection of HPV-16 in paraffin-embedded head and neck cancer specimens $[23,24]$. All tumours were stained for p16 on immunohistochemistry, followed by GP 5+/6+ PCR when p16 staining was positive.

\section{Immunohistochemistry}

TMAs were stained for KLK5, KLK7 and SPINK5 according to the manufacturer's protocol and as previously described [25]. In brief, 4 - $\mu$ m-thick paraffin sections were deparaffinised. After blocking of endogenous peroxidase and antigen retrieval by pepsin, the TMA slides were incubated for $60 \mathrm{~min}$ with different dilutions of the primary antibodies: KLK5 (AF1108, R\&D Sys-

(b), OSCC score: normal intensity $(1) \times$ proportion $(100 \%)=100($ c), OSCC score: $2 \times 75 \%=150$ (d). KLK5 staining: normal mucosa (e), no staining (f), OSCC score: $1 \times 75 \%=75(\mathbf{g})$, OSCC score: $2 \times$ $50 \%=100(\mathbf{h})$. KLK7 staining: normal mucosa (i), no staining (j), OSCC score: $1 \times 50 \%=50(\mathbf{k})$, OSCC score: $2 \times 40 \%=80(\mathbf{I})$. 
To determine the score for each TMA core, appropriate controls of normal squamous epithelium were used. Protein expression was scored for both its intensity in tumour cells relative to normal epithelium (normal $=2$, weaker $=1$, total loss $=0$ ) and the percentage of tumour cells in the tissue section with such a specific intensity. The product of these 2 scoring variables resulted in a scoring range of $0-200$, where a score of ' 0 ' represented a complete loss of protein expression in all tumour cells and '200' represented normal expression throughout the tumour (fig. 2). Co-expression of the 2 KLKs was defined as absent (0) if the sample showed a complete loss of expression for both KLK5 and KLK7, and otherwise as non-absent (1).

Statistical Analysis

The Mann-Whitney U test was used to determine differences in expression between several clinicopathological parameters. Overall survival (OS) was defined as the length of the time from surgery to death from any cause. Disease-specific survival (DSS) was defined as the time from surgery to death due to disease. For univariate survival analysis, we dichotomized KLK5, KLK7 and SPINK5 expression into absent (0) and non-absent (1-200). Kaplan-Meier curves were plotted to visualize differences in survival between these 2 groups. The log-rank test was used to obtain statistical significance. Prognostic value was examined by univariate and multivariate analyses using the Cox proportional-hazards regression model.

All $\mathrm{p}$ values were based on two-tailed statistical analysis and $\mathrm{p}<0.05$ was considered significant. Statistical analysis was performed using the SPSS 20.0 statistical package (SPSS Inc., Chicago, Ill., USA).

\section{Results}

\section{Baseline Characteristics}

Clinical data and survival rates were retrieved from the medical records, with follow-up times in the range of $0-15$ years and a median of 45 months (table 1; online suppl. fig. 1a; for all online suppl. material, see www. karger.com/doi/10.1159/000381904). Kaplan-Meier plots on survival in groups of patients stratified by gender, pathological nodal status $(\mathrm{pN})$ and tumour stage are shown in online supplementary figure $1 \mathrm{~b}-\mathrm{d}$. As expected, tumour stage and $\mathrm{pN}$ represented the clinical factors that exhibited the strongest association with OS.

\section{Detection of HPV-16}

HPV-16 active tumours were determined likewise by means of a recently validated algorithm [23, 24]. Of all 83 OSCCs in the study, only 3 showed strong expression for p16. However, no HPV-16 positivity was detected in any of these 3 by GP 5+/6+ PCR.

\section{Gene Expression and Clinicopathological Parameters}

Analysis of the 83 OSCCs showed a statistically significant differential gene expression between lymph node-positive and lymph node-negative patients for KLK7 ( $p=0.020)$, but not for KLK5 and SPINK5. The lymph node-positive patients had significantly less KLK7 mRNA (see online suppl. fig. 2).

Analysis of the other parameters showed significantly less KLK5, KLK7 and SPINK5 mRNA in alcohol-consuming patients, and less KLK5 and KLK7 mRNA in tobacco-using patients and in tumours showing an absence of keratinization (tables 1-3).

\section{Gene Expression and Survival}

To illustrate the prognostic impact of the gene expression of KLK5, KLK7 and SPINK5, we performed a Kaplan-Meier analysis with samples dichotomized into 2 groups with expression levels smaller than and equal to the median and levels greater than the median for each respective gene. Online supplementary figure $3 \mathrm{a}-\mathrm{c}$ shows the results for the 3 genes in the complete OSCC cohort. Furthermore, we performed univariate Cox regression analysis of the 3 genes (suppl. table 1). None of the genes had an independent prognostic association with survival.

\section{Immunohistochemistry: Descriptive Analysis}

A total of 226 (68\%) tumour cores stained with KLK5 antibody, 224 (67\%) stained with KLK7 and 221 (67\%) stained with SPINK5 were available for analysis. Due to our inclusion criteria ( $\geq 2$ tumour cores available per case), 14 cases were missing for KLK5, 15 for KLK7 and 17 for SPINK5. The majority of the OSCCs in this cohort showed an almost total loss of expression for KLK5 (71\%), for KLK7 (59\%) and for SPINK5 (59\%) (online suppl. table 2).

\section{Immunohistochemistry and Clinicopathological}

\section{Parameters}

Lower protein expression levels of KLK5 and KLK7 in the TMA cohort were significantly associated with a positive smoking history and alcohol consumption. Furthermore, there was a comparable trend for SPINK5 protein expression and a positive smoking history. Current smokers or patients who had ceased smoking $<1$ year ago showed significantly less expression of KLK5 and KLK7 than those who had ceased $>1$ year ago or never-smokers $(\mathrm{p}=0.009 ; \mathrm{p}=0.011)$. Likewise, patients who consumed $1-4$ or $\geq 5$ units of alcohol per day showed a significantly greater loss of KLK5 and KLK7 protein expression than those who consumed alcohol occasionally or never ( $\mathrm{p}=$ $0.001 ; \mathrm{p}=0.012$ ).

Correlating the protein expression with the pathological characteristics (table 2), statistical analysis showed a significantly greater loss of KLK5, KLK7 and SPINK5 ex-
Leusink et al. 
Table 3. Correlations between gene (mRNA) and protein (IHC) expression of KLK5, KLK7 and SPINK5 and clinical and pathological parameters of the included OSCC cohort $(n=83)$

\begin{tabular}{|c|c|c|c|c|c|c|}
\hline & \multicolumn{6}{|l|}{$\mathrm{p}$ value } \\
\hline & \multicolumn{2}{|l|}{ KLK5 } & \multicolumn{2}{|l|}{ KLK7 } & \multicolumn{2}{|l|}{ SPINK5 } \\
\hline & mRNA & $\mathrm{IHC}$ & mRNA & IHC & mRNA & $\mathrm{IHC}$ \\
\hline \multicolumn{7}{|l|}{ Clinical characteristic } \\
\hline Smoking history & 0.002 & 0.009 & 0.004 & 0.011 & $0.052^{*}$ & $0.067^{*}$ \\
\hline Alcohol consumption & 0.013 & 0.001 & 0.003 & 0.012 & 0.045 & n.s. \\
\hline $\mathrm{cN}$ & 0.003 & n.s. & 0.007 & n.s. & n.s. & n.s. \\
\hline \multicolumn{7}{|l|}{ Pathological characteristic } \\
\hline $\mathrm{pN}$ & n.s. & n.s. & 0.020 & n.s. & n.s. & n.s. \\
\hline Differentiation & n.s. & 0.021 & n.s. & 0.013 & n.s. & 0.003 \\
\hline Keratinization & 0.040 & 0.004 & 0.020 & 0.001 & $0.087^{*}$ & 0.028 \\
\hline
\end{tabular}

Cases were stratified according to clinical and pathological characteristics. Smoking history was dichotomized to current smoker or having ceased smoking $<1$ year ago versus ex-smokers (ceased $>1$ year ago) and never-smokers. Alcohol consumption was dichotomized to $1-4$ or $\geq 5 \mathrm{U} /$ day versus occasionally or never. Clinical nodal status $(\mathrm{cN})$ and $\mathrm{pN}$ were dichotomized to $\mathrm{cN} 0$ versus $\mathrm{cN}+$ and $\mathrm{pN} 0$ versus $\mathrm{pN}+$, respectively. Differentiation was dichotomized to 'well' and 'moderate' versus 'poor' and 'undifferentiated'. Keratinization was dichotomized to present versus absent. IHC = Immunohistochemistry; n.s. = not significant. $\mathrm{p}$ values represent the Mann-Whitney $U$ test of these comparisons: ${ }^{*} \mathrm{p}>$ 0.05 and $p<0.10$ were considered clinically relevant $(\mathrm{p}<0.05$ was statistically significant). pression in patients with OSCCs that were poorly differentiated, undifferentiated $(\mathrm{p}=0.021 ; \mathrm{p}=0.013 ; \mathrm{p}=0.003)$ or classified as keratinization-absent $(\mathrm{p}=0.004 ; \mathrm{p}=0.001$; $\mathrm{p}=0.028$; table 3 ).

\section{Immunohistochemistry and Survival}

A Cox regression model was applied to identify any prognostic relevance for protein expression of KLK5, KLK7 and SPINK5. Furthermore, we added co-expression of KLK5 and KLK7 to this model. All protein expressions were dichotomized into no expression (score: 0 ) versus expression (score: 1). Co-expression of KLK5 and KLK7 scored 0 if both kallikreins scored 0 . Univariate analysis indicated a significant prognostic impact in OS in OSCC samples of KLK5 protein expression $(\mathrm{HR}=0.41$, CI $0.20-0.85, \mathrm{p}=0.017$ ) and of KLK7 protein expression $(\mathrm{HR}=0.43$, CI $0.22-0.86, \mathrm{p}=0.016$; table 4$)$. SPINK5 protein expression did not have any prognostic impact on OS. Kaplan-Meier survival plots are shown in online supplementary figure $3 \mathrm{~d}-\mathrm{f}$.

The prognostic impact on OS of the co-expression of KLK5 and KLK7 was even stronger than the impact of KLK5 or KLK7 alone ( $\mathrm{HR}=0.36$, CI 0.18-0.74, $\mathrm{p}=0.005)$. We thus had reason to apply a multivariate Cox regression model with co-expression of KLK5 and KLK7 along with known prognostic markers like age, stage and $\mathrm{pN}$.
Independent of stage and $\mathrm{pN}$ but corrected for age, coexpression showed a significant impact on OS $(\mathrm{HR}=0.32$, CI $0.16-0.66, \mathrm{p}=0.002$; table 4 ; fig. $3 \mathrm{~b}$ ). In this TMA cohort, co-expression of KLK5 and KLK7 showed 2- and 5 -year survival rates of 47 and $24 \%$ for patients with a complete loss of co-expression (score 0 ) and of 80 and $58 \%$ for patients with co-expression (score 1), respectively (fig. 3a).

With regard to DSS, patients with a complete loss of co-expression had a shorter DSS than patients with coexpression, with a 2-year survival rate of 53 versus $82 \%$ and a 5-year survival rate of 36 versus $74 \%$, respectively $(\mathrm{HR}=0.34$, CI 0.15-0.78, $\mathrm{p}=0.011$; table 5; fig. $3 \mathrm{c}-\mathrm{d})$. Multivariate analysis showed an independent significant impact of co-expression on DSS corrected for $\mathrm{pN}$ ( $\mathrm{HR}=$ 0.36 , CI 0.15-0.87, $\mathrm{p}=0.022$; table 5).

The follow-up time of patients without an event was 80.3 months (median 71.4 months).

\section{Discussion}

The aim of this study was to evaluate the role of the proteases KLK5 and KLK7 as biomarkers of LNM and prognosis in OSCC. We show that in this cohort only underexpression of KLK7 mRNA correlated with LNM in 
Table 4. Univariate and multivariate OS Cox regression model for protein expression of KLK5, KLK7 and co-expression of KLK5 and KLK7 in the OSCC TMA cohort, dichotomized into no expression (score 0 ) versus expression (score 1 ) and the most important prognostic parameters (age, stage and $\mathrm{pN}$ )

\begin{tabular}{llll}
\hline & HR & 95\% CI & p value \\
\hline Univariate analysis & & & \\
$\quad$ Age $^{\mathrm{a}}$ & 1.75 & $0.94-3.27$ & 0.078 \\
Tumour stage $^{\mathrm{b}}$ & 2.37 & $1.10-5.11$ & 0.028 \\
pN $^{\mathrm{c}}$ & 2.19 & $1.17-4.09$ & 0.014 \\
KLK5 expression & 0.41 & $0.20-0.85$ & 0.017 \\
KLK7 expression & 0.43 & $0.22-0.86$ & 0.016 \\
KLK5 + KLK7 co-expression & 0.36 & $0.18-0.74$ & 0.005 \\
Multivariate analysis & & & \\
$\quad$ KLK5 + KLK7 co-expression & & & \\
$\quad$ corrected for age & 0.32 & $0.16-0.66$ & 0.002 \\
\hline & a $<60$ vs. $\geq 60$ years; ${ }^{\mathrm{b}}$ I, II vs. III, IV; ${ }^{\mathrm{c}}$ pN0 vs. pN+. & \\
\hline
\end{tabular}

OSCC patients, which is in line with the LNM-predicting gene expression signature in OSCC [21] containing KLK5, KLK7 and SPINK5 and other genes. Even though mRNA of KLK5 and SPINK5 was not significantly associated with LNM in this cohort, the correlations were similar (online suppl. fig. 2).

The majority of the OSCC samples showed a total/almost total loss of expression of KLK5 (71\%), KLK7 (59\%) and SPINK5 (59\%). Our observation concerning SPINK5 expression is consistent with 2 previous studies that demonstrated down-regulation of SPINK 5 mRNA expression in HNSCC. In the first study, a very small panel of 3 oropharynx tumours was investigated [17], whereas the second study obtained genome-wide transcriptomic profiles of 53 primary oral tongue SCC [18]. The second study, however, focused on identifying the specific genes associated with oral tongue SCC and did not use or provide complete clinical and pathological data on the patients and samples tested. Next, our observation concerning the (almost) total loss of KLK5 and KLK7 expression appears, at first glance, to be in contradiction to a previous study by Pettus et al. [13] that reported abundant protein expression of KLK5, KLK7, KLK8 and KLK10 in 50 OSCCs. However, analysis of the sub-sites and differentiation grades reveals that $58 \%$ of the samples in their study originated from the oral tongue (vs. 39\% in our cohort; table 1 ) and that $61 \%$ were well-differentiated, $30 \%$ were moderately differentiated and $9 \%$ were poorly differentiated (vs. 4,77 and $17 \%$ in our cohort; table 2). Floor-ofmouth tumours showed lower expression than tongue tu-
Table 5. Univariate and multivariate DSS Cox regression model for protein expression of KLK5, KLK7 and co-expression of KLK5 and KLK7 in the OSCC TMA cohort, dichotomized into no expression (score 0 ) versus expression (score 1 ) and the most important prognostic parameters (age, stage and $\mathrm{pN}$ )

\begin{tabular}{|c|c|c|c|}
\hline & HR & $95 \%$ CI & $\mathrm{p}$ value \\
\hline \multicolumn{4}{|l|}{ Univariate analysis } \\
\hline Age $^{\mathrm{a}}$ & 1.01 & $0.48-2.12$ & 0.978 \\
\hline Tumour stage ${ }^{b}$ & 4.01 & $1.21-13.29$ & 0.023 \\
\hline $\mathrm{pN}^{\mathrm{c}}$ & 4.10 & $1.66-10.15$ & 0.002 \\
\hline KLK5 expression & 0.48 & $0.20-1.13$ & 0.094 \\
\hline KLK7 expression & 0.42 & $0.18-0.96$ & 0.040 \\
\hline KLK5 + KLK7 co-expression & 0.34 & $0.15-0.78$ & 0.011 \\
\hline \multicolumn{4}{|l|}{ Multivariate analysis } \\
\hline $\begin{array}{l}\text { KLK5 + KLK7 co-expression } \\
\text { corrected for } \mathrm{pN}\end{array}$ & 0.36 & $0.15-0.87$ & 0.022 \\
\hline
\end{tabular}

mours (data not shown). Furthermore, poorly differentiated and undifferentiated tumours had lower expression of both KLK5 and KLK7. These clinical and pathological differences between the samples of the 2 studies highlight the influence of the composition of the studied population on the result. From this point of view, the conclusion stated by Pettus et al. [13] that it was mostly the well-differentiated OSCCs originating from the tongue that had abundant expression of KLK5 and KLK7 is actually in agreement with our observation.

In an attempt to investigate the functional role of KLK5, KLK7 and SPINK5 in OSCC, we analyzed the expression of all 3 together. KLK5 and KLK7 play important roles in skin desquamation where the shedding of corneocytes occurs due to the proteolytic processing of junctional structures like corneodesmosin $[5,26]$. SPINK5 regulates this desquamation by inhibiting KLK5 and KLK7. The loss of SPINK5, in Netherton's syndrome for instance, results in unregulated proteolysis in the outer layers of the epidermis, causing a defective barrier function [26]. Normal oral squamous cells have a high expression of KLK5, KLK7 and SPINK5 (fig. 2d, h, 1), which suggests a similar role for these proteases and their inhibitor in the normal oral mucosa. Our data (table 3) show that OSCCs that are able to produce keratin or keratin whirls (i.e. fig. 2f; high KLK7 expression) have a significantly greater expression of KLK5, KLK7 and SPINK5. It is interesting to speculate that the role of KLK5 and KLK7 and the balance with their inhibitor SPINK5 might be related and limited just to the process of keratinization. 

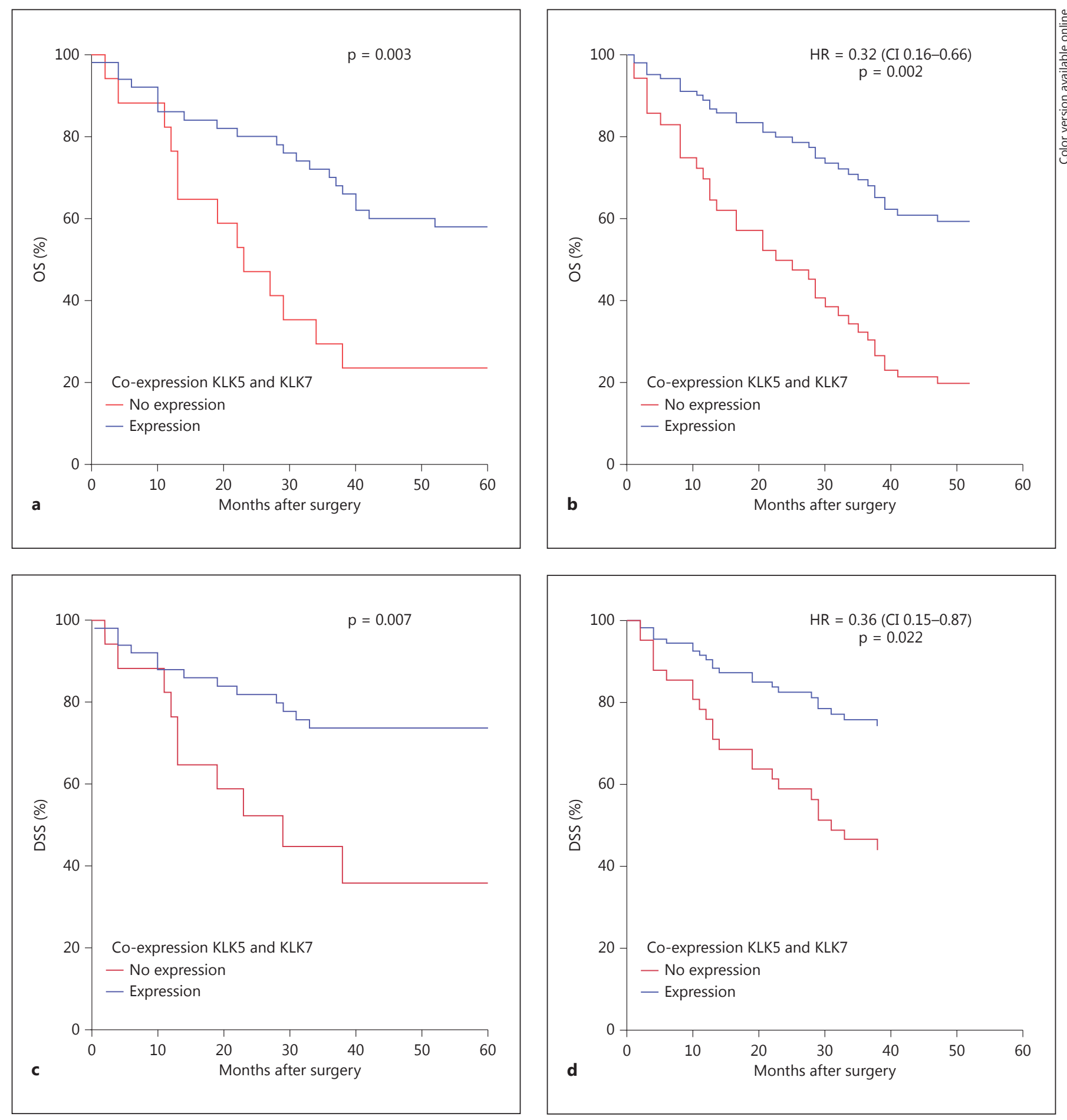

Fig. 3. Survival plots of all OSCC patients $(n=83)$ included in the TMA expression analysis stratified according to the co-expression level of KLK5 and KLK7: 0 or no protein expression of both KLKs (red) versus 1-400, the sum of both KLK protein expression (blue). OS plotted by Kaplan-Meier analysis (a) and Cox regression anal-

ysis (b). DSS plotted by Kaplan-Meier analysis (c) and Cox regression analysis (d). a, c The log-rank test of this group comparison is represented, and the $\mathrm{p}$ values therefore differ from the significance levels of the Cox regression analysis $(\mathbf{b}, \mathbf{d})$. 
At any rate, we did not observe any uncontrolled KLK activity in the OSCCs with low SPINK5 expression, nor could we correlate this to a phenomenon linked to tumour progression, like LNM.

Although many correlations with clinicopathological parameters between gene and protein expression as depicted in table 2 are similar, the discrepancies can be explained in two ways. Firstly, changes in mRNA level do not necessarily correlate one-to-one with the effect on protein level and vice versa, due to post-transcriptional modifications such as increased or decreased mRNA stability. Secondly, gene expression data were acquired using biopsies taken at the border of the primary tumour and samples were included if they consisted of at least $50 \%$ tumour cells [20]. The other part of the sample contained stromal cells and epithelial cells adjacent to the tumour. Consequently, gene expression was measured using tumour, stromal and epithelial cells. KLK5, KLK7 and SPINK5 are highly expressed in all of these cells. On the other hand, protein expression was acquired by scoring immunoreactivity in the tumour cells only. This explains why a concurrent loss of KLK5 and KLK7 was found in the protein expression data but could not be found in the gene expression data.

A concurrent loss of KLK5 and KLK7 predicted OS in the univariate and multivariate survival analyses corrected for age and $\mathrm{pN}$. Correction of the OS model by age resulted in a decrease of the HR to 0.29 , which means that older patients with a positive co-expression have a better survival than younger patients with a complete loss of expression of both KLK5 and KLK7. Correction of the DSS model by $\mathrm{pN}$ resulted in an increase of the HR to 0.39 which means that patients with a positive co-expression survive better than patients without; however, this difference in survival decreases when the patient has a positive $\mathrm{pN}$.

Before concurrent loss of KLK5 and KLK7 could serve as a prognostic marker, this TMA-based result needs validation in several steps. First, comparison of the TMA slides with whole-tissue sections of the same cohort of primary tumours is needed to check if concurrent loss can also be diagnosed on the latter. Secondly, a prospective study based on pre-operative biopsies is needed to validate the concurrent loss of KLK5 and KLK7 as a prognostic marker.

To date, no single molecular marker has been able to reliably predict occult LNM in OSCC patients. Recently, an LNM-predicting gene expression signature was validated [21] and combined with a sentinel lymph-node biopsy procedure [4]. This could even prove to be helpful in decision-making with regard to the clinically nodenegative neck. Whether a loss of SPINK5 tips the balance to more protease activity by KLK5 and KLK7, and whether such an imbalance may identify patients with aggressive tumour behavior cannot be confirmed by our data and has still to be elucidated. However, the concurrent loss of KLK5 and KLK7 does identify OSCC patients with poor clinical outcome and may therefore act as a prognostic marker.

\section{Acknowledgments}

S.M.W. is funded by the Dutch Cancer Society (Clinical Fellowship: 2011-4964).

\section{References}

1 Jemal A, Bray F, Center MM, Ferlay J, Ward E, Forman D: Global cancer statistics. CA Cancer J Clin 2011;61:69-90.

$\checkmark 2$ Ang KK, Harris J, Wheeler R, Weber R, Rosenthal DI, Nguyen-Tan PF, Westra WH, Chung CH, Jordan RC, Lu C, Kim H, Axelrod R, Silverman CC, Redmond KP, Gillison ML: Human papillomavirus and survival of patients with oropharyngeal cancer. N Engl J Med 2010;363:24-35.

- 3 Leemans CR, Braakhuis BJ, Brakenhoff RH: The molecular biology of head and neck cancer. Nat Rev Cancer 2011;11:9-22.

-4 Leusink FK, van Es RJ, de Bree R, Baatenburg de Jong RJ, van Hooff SR, Holstege FC, Slootweg PJ, Brakenhoff RH, Takes RP: Novel di- agnostic modalities for assessment of the clinically node-negative neck in oral squamous-cell carcinoma. Lancet Oncol 2012;13: e554-e561.

5 Borgono CA, Diamandis EP: The emerging roles of human tissue kallikreins in cancer. Nat Rev Cancer 2004;4:876-890.

-6 Emami N, Diamandis EP: Utility of kallikrein-related peptidases (KLKs) as cancer biomarkers. Clin Chem 2008;54:1600-1607.

7 Lilja H, Ulmert D, Vickers AJ: Prostate-specific antigen and prostate cancer: prediction, detection and monitoring. Nat Rev Cancer 2008;8:268-278.

-8 Sotiropoulou G, Pampalakis G, Diamandis EP: Functional roles of human kallikrein- related peptidases. J Biol Chem 2009;284: 32989-32994.

-9 Dong Y, Kaushal A, Brattsand M, Nicklin J, Clements JA: Differential splicing of KLK5 and KLK7 in epithelial ovarian cancer produces novel variants with potential as cancer biomarkers. Clin Cancer Res 2003;9:1710-1720.

10 Yousef GM, Polymeris ME, Yacoub GM, Scorilas A, Soosaipillai A, Popalis C, Fracchioli S, Katsaros D, Diamandis EP: Parallel overexpression of seven kallikrein genes in ovarian cancer. Cancer Res 2003;63:2223-2227.

11 Li X, Liu J, Wang Y, Zhang L, Ning L, Feng Y: Parallel underexpression of kallikrein 5 and kallikrein 7 mRNA in breast malignancies. Cancer Sci 2009;100:601-607. 
12 Talieri M, Devetzi M, Scorilas A, Prezas P, Ardavanis A, Apostolaki A, Karameris A: Evaluation of kallikrein-related peptidase 5 expression and its significance for breast cancer patients: association with kallikrein-related peptidase 7 expression. Anticancer Res 2011;31:3093-3100.

13 Pettus JR, Johnson JJ, Shi Z, Davis JW, Koblinski J, Ghosh S, Liu Y, Ravosa MJ, Frazier S, Stack MS: Multiple kallikrein (KLK 5, 7, 8, and 10) expression in squamous cell carcinoma of the oral cavity. Histol Histopathol 2009; 24:197-207.

14 Deraison C, Bonnart C, Lopez F, Besson C, Robinson R, Jayakumar A, Wagberg F, Brattsand M, Hachem JP, Leonardsson G, Hovnanian A: LEKTI fragments specifically inhibit KLK5, KLK7, and KLK14 and control desquamation through a $\mathrm{pH}$-dependent interaction. Mol Biol Cell 2007;18:3607-3619.

15 Egelrud T, Brattsand M, Kreutzmann P, Walden M, Vitzithum K, Marx UC, Forssmann WG, Magert HJ: Hk5 and Hk7, two serine proteinases abundant in human skin, are inhibited by LEKTI domain 6. Br J Dermatol 2005; 153:1200-1203.

16 Schechter NM, Choi EJ, Wang ZM, Hanakawa Y, Stanley JR, Kang Y, Clayman GL, Jayakumar A: Inhibition of human kallikreins 5 and 7 by the serine protease inhibitor lympho-epithelial Kazal-type inhibitor (LEKTI). Biol Chem 2005;386:1173-1184.
17 Gonzalez HE, Gujrati M, Frederick M, Henderson Y, Arumugam J, Spring PW, Mitsudo K, Kim HW, Clayman GL: Identification of 9 genes differentially expressed in head and neck squamous cell carcinoma. Arch Otolaryngol Head Neck Surg 2003;129:754-759.

18 Ye H, Yu T, Temam S, Ziober BL, Wang J, Schwartz JL, Mao L, Wong DT, Zhou X: Transcriptomic dissection of tongue squamous cell carcinoma. BMC Genomics 2008;9:69.

19 Roepman P, Kemmeren P, Wessels LF, Slootweg PJ, Holstege FC: Multiple robust signatures for detecting lymph node metastasis in head and neck cancer. Cancer Res 2006;66: 2361-2366.

20 Roepman P, Wessels LF, Kettelarij N, Kemmeren P, Miles AJ, Lijnzaad P, Tilanus MG, Koole R, Hordijk GJ, van der Vliet PC, Reinders MJ, Slootweg PJ, Holstege FC: An expression profile for diagnosis of lymph node metastases from primary head and neck squamous cell carcinomas. Nat Genet 2005; 37:182-186.

21 van Hooff SR, Leusink FK, Roepman P, Baatenburg de Jong RJ, Speel EJ, van den Brekel MW, van Velthuysen ML, van Diest PJ, van Es RJ, Merkx MA, Kummer JA, Leemans CR, Schuuring E, Langendijk JA, Lacko M, De Herdt MJ, Jansen JC, Brakenhoff RH, Slootweg PJ, Takes RP, Holstege FC: Validation of a gene expression signature for assessment of lymph node metastasis in oral squamous cell carcinoma. J Clin Oncol 2012;30:4104-4110.
22 van Diest PJ: No consent should be needed for using leftover body material for scientific purposes. BMJ 2002;325:648-651.

23 Rietbergen MM, Leemans CR, Bloemena E, Heideman DA, Braakhuis BJ, Hesselink AT, Witte BI, Baatenburg de Jong RJ, Meijer CJ, Snijders PJ, Brakenhoff RH: Increasing prevalence rates of HPV attributable oropharyngeal squamous cell carcinomas in the Netherlands as assessed by a validated test algorithm. Int J Cancer 2013;132:1565-1571.

24 Smeets SJ, Hesselink AT, Speel EJ, Haesevoets A, Snijders PJ, Pawlita M, Meijer CJ, Braakhuis BJ, Leemans CR, Brakenhoff RH: A novel algorithm for reliable detection of human papillomavirus in paraffin embedded head and neck cancer specimen. Int J Cancer 2007;121: 2465-2472.

25 Noorlag R, van der Groep P, Leusink FK, van Hooff SR, Frank MH, Willems SM, van Es RJ: Nodal metastasis and survival in oral cancer: association with protein expression of SLPI, not with LCN2, TACSTD2, or THBS2. Head Neck 2014, Epub ahead of print.

26 Descargues P, Deraison C, Bonnart C, Kreft M, Kishibe M, Ishida-Yamamoto A, Elias P, Barrandon Y, Zambruno G, Sonnenberg A, Hovnanian A: SPINK5-deficient mice mimic Netherton syndrome through degradation of desmoglein 1 by epidermal protease hyperactivity. Nat Genet 2005;37:56-65. 